\title{
DESIGUALDADE DE OPORTUNIDADES NO ACESSO AO ENSINO SUPERIOR NO BRASIL: UMA COMPARAÇÃO ENTRE 2003 E 2013
}

\author{
Márcia Marques de Carvalho* \\ FÁbio D. WALTENBERG ${ }^{\dagger}$
}

\begin{abstract}
Resumo
Apesar dos avanços no ensino fundamental e médio nas últimas décadas, e da ampliação de vagas no ensino superior, apenas $12 \%$ dos jovens em idade universitária estão cursando o ensino superior no Brasil, contra $21 \%$ na Argentina, $65 \%$ nos EUA e $70 \%$ na Suécia. Neste estudo, a partir dos dados mais recentes da Pnad disponíveis (2013) e dos dados de uma década antes (2003, pouco antes do advento de políticas de ação afirmativa), inicialmente traçam-se perfis de grupos vulneráveis e não vulneráveis no acesso ao ensino superior. Depois, com base no índice de oportunidades humanas (Barros et al. 2009), e fazendo-se uso de regressões de variável dependente binária, mensuramos a desigualdade de oportunidades no acesso ao ensino superior para os dois anos. Os resultados indicam que houve realocação de oportunidades dos grupos não vulneráveis para os grupos vulneráveis, e que o acesso ao ensino superior também aumentou levemente no espaço de uma década. Contudo, o índice de oportunidades humanas ao acesso ao ensino superior no Brasil $(\mathrm{IOH}=0,281 \mathrm{em}$ 2013) está muito longe da situação ideal $(\mathrm{IOH}=1)$, que ocorre quando o acesso é universal e não há desigualdade de oportunidades no acesso. Por fim, aplicou-se aos indicadores obtidos uma decomposição por fator (de Shapley), cujos principais resultados são a importância da instrução do chefe e da renda domiciliar como circunstâncias limitadoras, e também uma contribuição moderada da cor/raça para a desigualdade de oportunidades no acesso ao ensino superior no Brasil.
\end{abstract}

Palavras-chave: Índice de Oportunidades Humanas; Regressão Logística; Decomposição de Shapley.

\footnotetext{
Abstract

${ }^{*}$ Professora do Departamento de Estatística da Universidade Federal Fluminense (UFF). Pesquisadora do centro de Estudos sobre Desigualdade e Desenvolvimento (CEDE). Niterói, Rio de Janeiro, Brasil. E-mail: mcarvalho@est.uff.br

† Professor do Departamento de Economia da Universidade Federal Fluminense (UFF). Pesquisador do centro de Estudos sobre Desigualdade e Desenvolvimento (CEDE). Niterói, Rio de Janeiro, Brasil. E-mail: waltenberg@economia.uff.br
} 
In spite of overall improvements in basic and high school education levels in the last decades, and of an increase in the supply of higher education, only $12 \%$ of Brazilian youths in the expected age are attending higher education in Brazil, against $21 \%$ in Argentina, $65 \%$ in the USA and $70 \%$ in Sweden. In this study, based on the most recent Pnad data (2013) and on data from ten years earlier (2003, just before the implementation of affirmative action policies), we obtained profiles of vulnerable and nonvulnerable groups in terms of access to higher education in Brazil. Then through the index of human opportunities (Barros et al. 2009), and making use of binary dependent variable regressions, we were able to measure inequality of opportunity in terms of access to higher education for both years. Results indicate that a reallocation of opportunities from nonvulnerable to vulnerable groups has taken place, and that access to higher education has also risen slightly in the course of one decade. However, the index of human opportunity as applied to higher education in Brazil $(\mathrm{HOI}=0.281$ in 2013) is very far from the ideal situation $(\mathrm{HOI}=1)$, which occurs when access is universal and there is no inequality of opportunity in the access. Finally, we have applied a Shapley decomposition to the calculated indices, and the main results are the substantial contribution of household-head's education level and the household's income to inequality of opportunity, and also a moderate impact of race.

Keywords: Human Opportunity Index; Logistic Regression; Shapley Decomposition.

JEL classification: C43, D30, D63

DOI: http://dx.doi.org/10.1590/1413-8050/ea 124777 


\section{Introdução}

Estudar as dificuldades e os gargalos no acesso ao ensino superior no Brasil é relevante por vários motivos. O primeiro é a nossa defasagem de pessoas com esse nível de ensino, visto que, ao contrário de muitos países, o Brasil tem menos de $20 \%$ da sua população adulta com esta qualificação. Isso afeta a produtividade e a capacidade da economia brasileira em adquirir e desenvolver novas tecnologias. Pessoas mais instruídas ganham mais e estão menos expostas ao desemprego, elementos que contribuem para uma maior qualidade de vida para elas e sua família.

Como é amplamente sabido, a educação afeta diversas dimensões da vida social e econômica de um país, além de produzir benefícios que são privadamente apropriados pelos indivíduos, tais como habilidades, atitudes e valores (Barr 2012). Há diversas evidências que mostram que quanto mais se investe em educação, além dos efeitos diretos positivos na economia do país, maior é o retorno à sociedade em termos de bem-estar, redução das desigualdades e das taxas de fecundidade e mortalidade (Mendonça 2000). No caso da educação superior, os ganhos são mais elevados e os impactos no mercado de trabalho e na capacidade de absorção de inovação tecnológica e na produtividade são ainda mais expressivos.

No Brasil, a conclusão de um curso de graduação é acompanhada por uma baixa taxa de desemprego e por um retorno financeiro que, em média, é 2,6 vezes maior do que os obtidos por aqueles que pararam os estudos no ensino médio (Carvalho 2011). Em termos comparativos esse retorno do ensino superior é alto quando comparado com o observado nos países desenvolvidos: nos EUA é de 1,77, na Alemanha, 1,67; no Reino Unido, 1,54, na França, 1,50 e no Canadá, 1,42, segundo dados da OCDE (2011). Esse alto retorno no Brasil se deve ao fato de ser pequena a proporção da população adulta brasileira ( 25 a 64 anos) que completou o ensino superior, limitando, dessa forma, a oferta dessa mão-de-obra. Segundo dados da Pnad/2011, apenas $11 \%$ da população adulta brasileira tinham curso de graduação, enquanto no Canadá essa proporção chega a $49 \%$, nos Estados Unidos, $41 \%$, no Japão, $43 \%$, no Reino Unido, 33\% e na Alemanha, 25\%.

O momento é oportuno para se estudar o acesso ao ensino superior por dois motivos. O primeiro é no sentido de se compreender melhor as políticas de ação afirmativa no acesso ao ensino superior, uma vez que muitas instituições públicas passaram a adotar políticas deste tipo ao longo da década passada e agora as instituições federais são obrigadas a reservarem uma proporção das suas vagas para egressos do ensino médio público com combinações de renda familiar e cor/raça (Lei no 12.711 de 29 de agosto de 2012, doravante chamada de "Lei das Cotas"). O segundo é de aproveitar o momento do bônus demográfico brasileiro. Perdemos a primeira "onda" da população de 18 a 24 anos que ocorreu entre 2000 e 2010 e causou um aumento de dois milhões de pessoas deste grupo etário em apenas uma década. A próxima onda desse grupo etário irá ocorrer entre 2016 e 2026. Estamos neste momento (2015) passando pela onda do grupo etário de 25 a 34 anos que terá o seu ápice em 2016 e terminando em 2020.

Outra característica do ensino superior no Brasil é a pouca diversidade socioeconômica entre os estudantes. De fato, embora entre 2006 e 2008, 85\% dos concluintes do ensino médio proviessem do ensino médio público, dos indivíduos que ingressaram nos cursos de graduação no Brasil nesse período, 
essa proporção cai para somente 57\% (MEC/Inep). Na mesma linha, em 2009, enquanto $45 \%$ das pessoas com ensino médio completo provinham de famílias relativamente pobres (com renda familiar de até 3 salários mínimos), entre os ingressantes do ensino superior, essa proporção caía para 39\%. Considerando apenas as pessoas com ensino médio completo, 50,3\% se declararam não brancas enquanto entre os ingressantes dos cursos de graduação a incidência desse grupo era de apenas $36,4 \%$.

De acordo com a teoria de igualdade de oportunidades do economista Roemer (1998), muito em voga atualmente (Fleurbaey 2008, Ferreira \& Gignoux 2014, Pignataro 2012, Ramos \& Van De Gaer 2012), quando existe subrepresentação por parte de um grupo socioeconômico, definido pela sociedade como relevante e legítimo, no acesso a um serviço ou vantagem - como ocorre com o acesso de certos grupos ao ensino superior no Brasil - pode-se estar diante de um problema de desigualdade de oportunidades, se porventura a dificuldade de obter acesso ao serviço ou vantagem tiver sido causada, sobretudo, por circunstâncias desfavoráveis.

No caso do ensino superior, uma tentativa de mitigar o problema de acesso limitado de certos grupos consiste na aplicação de políticas de ação afirmativa. As ações afirmativas podem ser compreendidas como programas que buscam prover oportunidades ou outros benefícios para pessoas pertencentes a grupos específicos, alvo de discriminação ou com pouco acesso a recursos (IPEA 2008). Têm sido aplicadas em inúmeros países e em diferentes etapas da educação, bem como no mercado de trabalho. No Brasil, têm se concentrado no acesso aos cursos de graduação, por meio de diferentes instrumentos: cotas e bônus, ditas "raciais" ou "sociais". As "raciais" utilizam como critério a cor/raça do aluno, de acordo com auto-declaração. Os critérios "sociais" baseiam-se na renda familiar que comprove carência ou no fato de o aluno ser oriundo do ensino médio público, ou seja, de escolas municipais, estaduais ou federais ou de cursos supletivos presenciais de educação de jovens e adultos. Há casos em que ambos os critérios são considerados simultaneamente, quando vagas são reservadas, por exemplo, a alunos negros pobres.

No dia 26 de abril de 2012 o Supremo Tribunal Federal (STF) considerou constitucional a política de reservas de vagas para negros e índios para garantir o acesso destes grupos nas universidades públicas. A "Lei das Cotas" regulamentou as cotas nas universidades federais em todo o país e reserva um percentual das vagas oferecidas em cada curso de graduação e turno para alunos que estudaram todo o ensino médio em escolas públicas. Esse percentual deveria ser de $12,5 \%$ das vagas em $2013 ; 25 \%$ em $2014,37,5 \%$ em 2015 e $50 \%$ em 2016. Dessas vagas reservadas, a metade deve ser destinada a estudantes com renda familiar per capita de até 1,5 salário-mínimo e a outra metade a estudantes com renda superior a 1,5 salário-mínimo. Dentro de cada estrato de renda, será aplicada a porcentagem de cotas para pretos, pardos e indígenas observada em cada Estado e será definida pelo peso de cada uma dessas populações segundo o mais recente Censo do Instituto Brasileiro de Geografia e Estatística (IBGE). Cabe destacar que os percentuais definidos pela Lei não correspondem à representação proporcional dos grupos na população. Por exemplo, o percentual de vagas reservadas para egressos da escola pública em 2011 era de 50\% enquanto o Censo da Educação Básica do Ministério da Educação e Cultura mostrou que 85\% dos concluintes do ensino médio de todo o país eram de escolas públicas. Enquanto a Lei das Cotas reserva $50 \%$ das vagas para alunos egressos do ensino médio público com renda 
domiciliar per capita inferior a 1,5 sm, a Pesquisa Nacional por Amostra de Domicílios (Pnad) do IBGE mostra que esse grupo representa 86,7\% da demanda potencial ao ensino superior. Como existe uma relação forte entre a renda domiciliar per capita e a cor/raça autodeclarada, dentre os estudantes do ensino médio público com renda inferior a $1,5 \mathrm{sm}, 60 \%$ eram não brancos; e entre os estudantes do ensino médio público com renda superior a $1,5 \mathrm{sm}$, apenas $40 \%$ se autodeclararam não brancos. ${ }^{1}$

Uma política de ação afirmativa deve estar baseada na precisa identificação de segmentos sociais que, por desvantagens socioeconômicas, estão privados ou tem seu acesso limitado a um bem ou serviço. Em especial, quando se sabe que os retornos à educação superior são particularmente elevados, é de se questionar por que no Brasil, apesar desse enorme retorno em termos de aumento de salário e maior empregabilidade, muitos brasileiros não possuem este nível de ensino? Na década de 1980 e 1990 o gargalo poderia ser a insuficiência de vagas, mas entre 1999 e 2011, enquanto as vagas ofertadas nas instituições de ensino superior no país aumentaram 3,6 vezes, o número de ingressos no mesmo período aumentou 2,3 vezes (INEP 2011).

O presente trabalho traça um detalhado perfil dos matriculados dos cursos de graduação públicos e privados no Brasil a partir dos microdados da Pnad e identifica os grupos sociais mais vulneráveis ao acesso ao ensino superior e os menos vulneráveis. Em seguida, analisa quais são as características ou circunstâncias mais correlacionadas ao ingresso no ensino superior público e privado.

Uma vez identificados os fatores que restringem o acesso à educação superior e os segmentos sociais mais direta e intensamente afetados por essas restrições, ficarão evidentes para o leitor os elementos que poderiam justificar a adoção de políticas de ação afirmativa. Uma crítica que alguns pesquisadores têm feito com relação ao acesso à necessidade de se ampliar o acesso ao ensino superior é a de que nem todos os jovens que concluem o ensino médio gostariam de avançar os estudos e cursar a graduação. Uma pesquisa realizada em 2007 pelo Ipea em parceria como o Pnud e Cepal com jovens de 18 a 24 anos dos estados de São Paulo e Rio de Janeiro indagou que nível de ensino o jovem gostaria de alcançar. A resposta foi surpreendente: $77 \%$ dos jovens responderam que gostariam de alcançar o ensino superior, sendo que $48 \%$ deles ficariam satisfeitos com a graduação; $17 \%$ gostariam de cursar mestrado e $12 \%$ almejavam o doutoramento.

Para analisar a evolução da igualdade de oportunidades no acesso ao ensino superior no Brasil são utilizados os microdados da Pnad de 2013 (mais recente disponível) e também da Pnad de 2003 (antes da política de ações afirmativas no acesso ao ensino superior público). Com esses dados é possível mensurar a evolução, ao longo de um período de exatos dez anos, da taxa de cobertura do ensino superior e também a distribuição do acesso às vagas segundo as características dos alunos (circunstâncias) através do índice de dissimilaridade. Esses dois componentes multiplicados formam o Índice de Oportunidades Humanas (IOH), desenvolvido por Barros et al. (2009) para mensurar o acesso de crianças a um conjunto básico de bens e serviços, conforme proposto pelo Banco Mundial no seu Relatório de Desenvolvimento Mundial de 2006. Segundo o relatório, desigualdades de oportunidades cau-

\footnotetext{
${ }^{1} \mathrm{O}$ apêndice $\mathrm{A}$ apresenta um desenho esquemático com a distribuição percentual das vagas segundo a "Lei das Cotas" e a encontrada nos dados disponíveis.
} 
sam privações e têm como consequência desperdício de potencial humano. O método de decomposição de Shapley será aplicado ao índice de dissimilaridade para analisar os fatores mais associados à desigualdade no acesso ao ensino superior.

Tendo em vista os objetivos detalhados acima, o presente trabalho está organizado em três seções, além desta introdução e da conclusão. A segunda seção é conceitual e metodológica e apresenta a teoria da igualdade de oportunidades de Roemer. Além disso, traz os índices que tentam medir essa desigualdade. A seção traz também a metodologia da decomposição de Shapley. A seção 3 é empírica e apresenta uma análise quantitativa da desigualdade de oportunidades no acesso ao ensino superior, calculando os índices descritos no capítulo metodológico. Os resultados apontam que houve um aumento na cobertura do ensino superior público e privado entre 2003 e 2013 . Houve também um pequeno avanço em termos de distribuição destas vagas entre os grupos sociais: o índice de dissimilaridade caiu de 0,155 em 2003 para 0,108 em 2013, o que significa que a distribuição das vagas está ligeiramente mais homogênea entre os grupos.

\section{O índice de desigualdade de oportunidades e a decomposição de Shapley}

Segundo Peragine (2011), a teoria da igualdade de oportunidades foi formulada na filosofia política por Dworkin (1981), Arneson (1989) e Cohen (1989) e traduzida em modelos econômicos formais por Roemer $(1993,1998)$ e Fleurbaey (2008).

A teoria da igualdade de oportunidades baseia-se em três tipos de informação:

- Resultados: realizações educacionais, futuro rendimento, acesso a serviços básicos como água, luz e esgoto ou qualquer outra variável que expresse resultado;

- Circunstâncias: variáveis além da responsabilidade dos indivíduos (fora de seu controle) e que afetam a capacidade de atingir o resultado. Ex: gênero, etnia, local de nascimento, educação dos pais;

- Responsabilidades ou Esforço: variáveis pertencentes à esfera da responsabilidade dos indivíduos (esforço ou características de responsabilidade), em geral não observadas. Exemplos: esforça-se mais ou menos na escola, dedica-se mais ou menos tempo às tarefas escolares, trabalha mais ou menos horas etc.

A ideia básica da teoria é que as desigualdades determinadas pelo esforço são consideradas justas e somente as desigualdades resultantes das circunstâncias são consideradas eticamente inaceitáveis. ${ }^{2}$ Para ilustrar o que seria uma desigualdade injusta, isto é, devido às circunstâncias, vejamos o exemplo a seguir.

\footnotetext{
${ }^{2}$ A contribuição das variáveis não observáveis em geral acaba sendo creditada à conta do "esforço", não por assim determinar a teoria, mas sim por falta de alternativa metodológica melhor. Por essa razão, a repartição entre contribuição de "esforço" e de "circunstância" sempre merece ser interpretada com a ressalva de que as contribuições das circunstâncias estão subestimadas subestimada estará, portanto, a desigualdade de oportunidades reportada.
} 
Considere indivíduos de dois tipos no problema do acesso à educação superior no Brasil: ${ }^{3}$

- Tipo 1 consiste em indivíduos negros, morando na favela, com mãe chefe e vários irmãos, cujos pais não concluíram o ensino médio. Suponha que o nível de esforço do tipo 1 esteja entre 1 e 7 , numa escala de 0 a 10, com mediana 2,5 (c1).

- Tipo 2 consiste de indivíduos de classe média alta, morando com pai e mãe, com mais de 1 irmão e ambos os pais com ensino superior. Suponha que o nível de esforço do tipo 2 esteja entre 3 e 8 com mediana 5 (c2).

Suponha que João, do tipo 1, exerceu esforço de nível 5 , o que o coloca no $90^{\circ}$ centil da distribuição de seu tipo (Figura 1, distribuição do tipo 1, $\left.F\left(\frac{y}{c 1, e_{90}}\right)\right)$. Maria, do tipo 2, exerceu esforço de nível 7 , que também corresponde ao $90^{\circ}$ centil da distribuição do seu tipo (Figura 1, distribuição do tipo 2, $\left.G\left(\frac{y}{c 2, e_{90}}\right)\right)$.

\section{Distribuição do Tipo 1}

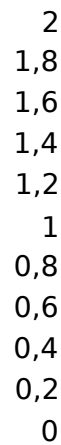

2

1,8

1,6

1,4

1,2

1

0,8

0,6

0,4

0,2

0
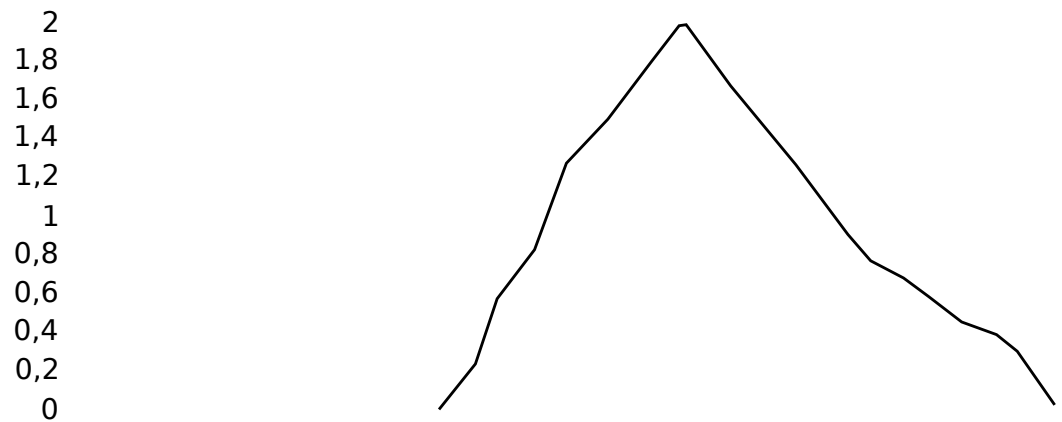

$\begin{array}{llllllllllllllll}0,5 & 1,0 & 1,5 & 2,0 & 2,5 & 3,0 & 3,5 & 4,0 & 4,5 & 5,0 & 5,5 & 6,0 & 6,5 & 7,0 & 7,5 & 8,0\end{array}$

Figura 1: Distribuição dos Resultados das pessoas do tipo 1 e do tipo 2

Suponha também que a nota mínima para passar no vestibular e ingressar na universidade seja 6. Neste caso, João não ingressaria na universidade

\footnotetext{
${ }^{3}$ Estamos supondo uma relação não decrescente entre esforço e resultado.
} 
porque obteve 5, e Maria ingressaria com sua nota 7. Entretanto, ambos exerceram o mesmo nível relativo de esforço e ficaram entre os $10 \%$ das melhores notas de seus tipos respectivos.

Roemer considera que, sob uma política de igualdade de oportunidades, os indivíduos que tenham exercido grau de esforço igual devem terminar com o mesmo resultado, ou seja:

$$
F\left(\frac{y}{c 1, e_{90}}\right)=G\left(\frac{y}{c 2, e_{90}}\right)
$$

A proposta de Roemer não implica que os resultados sejam igualados para todos. Ele propõe "nivelar o terreno", o que significa garantir que aqueles que aplicaram igual esforço terminem com igual realização, independente de suas circunstâncias. No ensino superior, as notas que medem o desempenho no vestibular dependem não só do esforço do indivíduo, mas também de outros fatores tais como a capacidade cognitiva. Esta, por sua vez, depende de fatores hereditários, da situação da família, da criação recebida na infância, da qualidade do ensino recebido, entre outras circunstâncias. As cotas ou reservas de vagas consideram aptos para admissão no ensino superior os indivíduos que mais se esforçaram dadas suas circunstâncias. Dessa forma justiça seria realizada, porque seriam tratados igualmente pessoas com antecedentes e características semelhantes. Em suma, o que Roemer propõe é uma meritocracia condicional ou uma meritocracia entre iguais. Quando consideramos somente as notas (mérito), segundo a teoria de Roemer, não estamos sendo justos porque estamos tratando igualmente pessoas diferentes, com antecedentes e características distintas. Esse é o princípio da compensação, segundo o qual a desigualdade de resultados derivada por diferentes dotações iniciais deve ser eticamente inaceitável e compensada pela política pública.

Roemer discute o escopo e a extensão do conceito de igualdade de oportunidades. Ele propõe que o conceito deva ser aplicado quando a oportunidade em questão é a aquisição de um atributo necessário para concorrer a um cargo (emprego ou carreira). Nesse contexto a igualdade de oportunidades no acesso ao ensino superior cabe, porque o acesso ao ensino superior no Brasil significa acesso a uma ocupação (médico, advogado, engenheiro) e ter uma educação superior é uma vantagem necessária para competir por determinados cargos. Roemer lembra, entretanto, que uma oportunidade é um acesso a uma vantagem (frase de Cohen 1989) mas o indivíduo é responsável em transformar esse acesso em vantagem pela aplicação do esforço.

Uma vez apresentado o modelo teórico de Roemer, o desafio agora é traduzir a teoria em medida. Pesquisas recentes têm procurado quantificar a desigualdade de oportunidades de um resultado, seja ele expresso em categorias, como os níveis educacionais e o acesso ou não a um bem ou serviço; ou expresso por uma variável contínua, como renda ou desempenho acadêmico.

Com relação à mensuração da desigualdade de oportunidades de variáveis categóricas, depois de Barros et al. (2009), outras propostas foram desenvolvidas. Podemos destacar as contribuições dos seguintes autores:

- Pignataro (2012) destaca que, no caso do acesso a um serviço ou a um nível educacional específico, deve-se utilizar o índice de oportunidades humanas (IOH) desenvolvido por Barros et al. (2009), uma vez que as categorias não envolvem um ordenamento; 
- Hoyos \& Narayan (2012) também utilizam o IOH para mensurar a desigualdade de oportunidades no acesso à educação e à saúde (vacinação) em 47 países. Além de mensurar a desigualdade de oportunidades, eles examinaram a contribuição de uma circunstância, a saber o gênero da criança, na desigualdade no acesso a esses serviços. Eles concluíram que, para a maioria dos países, a contribuição do sexo da criança para a frequência escolar e vacinação tende a ser baixa ou muito abaixo da contribuição de outras circunstâncias como status socioeconômico e a localização do domicílio (área urbana ou rural).

No Brasil, além do pioneiro trabalho de Barros et al. (2009), podemos destacar os trabalhos de:

- Dill \& Gonçalves (2012) analisam a igualdade de oportunidade no acesso a serviços como energia elétrica, água limpa, saneamento e escola, na linha de Barros et al. (2009), e sua evolução no Brasil, nos anos de 1999 e 2009, utilizando a Pnad. As características utilizadas como circunstâncias foram: gênero, raça, área de residência, gênero da pessoa de referência do domicílio, presença da mãe no domicílio, educação da pessoa de referência do domicílio, renda mensal domiciliar per capita e número de pessoas que vivem no domicílio.

- Diaz (2012) mensura a desigualdade de oportunidades de desempenho no ensino médio no Brasil a partir dos microdados do Saeb para o período 1995 a 2005. Utilizando a metodologia de Ferreira \& Gignoux (2008), que compara a desigualdade existente na distribuição alisada com a desigualdade na distribuição original, captando a desigualdade entre os grupos, os resultados indicam que a desigualdade de oportunidades foram menores em Língua Portuguesa ( $16 \%$ da desigualdade total, média do período) do que em Matemática ( $24 \%$ da desigualdade total, média do período).

- Carvalho et al. (2012) mensuram a igualdade de oportunidades educacionais utilizando os dados do Pisa, além de desenvolverem uma técnica alternativa e multidimensional que considera acesso, dissimilaridade na distribuição do acesso e desempenho dos estudantes.

\subsection{O Índice de Oportunidades Humanas $(\mathrm{IOH})$}

Após essa breve resenha da literatura sobre a mensuração da igualdade de oportunidades, cabe ressaltar que essa metodologia foi desenvolvida muito recentemente (desde 2005), principalmente a que trata de resultados categóricos (desde 2009).

Como o objetivo desse trabalho é mensurar o grau de desigualdade de oportunidades no acesso ao ensino superior (ou seja, uma variável binária) será calculado o índice de oportunidades humanas $(\mathrm{IOH})$, desenvolvido por Barros et al. (2009), que traduz a teoria de Roemer a resultados binários, mas que não foram utilizados no Brasil para acesso ao ensino superior. O IOH combina dois elementos:

- O nível de cobertura do acesso ao bem ou serviço em estudo na sociedade $(\hat{p})$; 
- O grau em que o acesso a esse bem ou serviço depende de variáveis que não são de responsabilidade do indivíduo (circunstâncias), tais como gênero, etnia, local de nascimento e educação dos pais. Essa mensuração é feita via índice de dissimilaridade (D), comumente utilizado em sociologia, e que mede a proporção do total de recursos (ou pessoas) que deveria ser realocada para restabelecer, no caso em tela, a igualdade de oportunidades. O índice D é calculado da seguinte forma:

$$
D=\frac{1}{2 \hat{p}} \sum_{k} w_{k}\left(p_{k}-\hat{p}\right)
$$

onde:

$k$ denota o grupo não-vulnerável, isto é, com acesso ao ensino superior $(p>\hat{p})$;

$p_{k}$ é a probabilidade de acesso do grupo $k$ e $\hat{p}$ a taxa de cobertura média da população;

$w_{k}$ é a participação do grupo não vulnerável $k$ no total da população.

$\mathrm{O}$ IOH combina acesso a um bem ou serviço $(\hat{p})$ e a forma de alocação (D) com base no princípio da igualdade de oportunidade da seguinte forma:

$$
I O H=\hat{p}(1-D)
$$

De maneira intuitiva, o IOH capta a cobertura do bem ou serviço que é adequadamente alocada entre os diversos grupos de circunstâncias. Se o acesso dos indivíduos é independente de suas circunstâncias $\left(p_{k}=\hat{p} \operatorname{logo} D=0\right)$ então o IOH será igual à taxa de cobertura do bem e serviço. O IOH é igual a 1 quando o acesso é universal $(\hat{p}=1)$ e não há desigualdade no acesso $\left(p_{j}=\hat{p}\right)$.

Observe que qualquer realocação de oportunidade dos grupos "não vulneráveis" (aqueles com $p_{k}>\hat{p}$ ) para os grupos "vulneráveis" (aqueles com $p_{k}<\hat{p}$ ) reduzirá $\mathrm{D}$ e aumentará o $\mathrm{IOH}$, que é o efeito esperado das ações afirmativas no Brasil.

Seguindo Hoyos \& Narayan (2012), o IOH possui algumas propriedades importantes, tais como:

a) sensibilidade à escala: se a cobertura para todos os grupos muda aditivamente ou de forma multiplicativa pelo mesmo fator $\mathrm{k}$, o IOH também muda (de forma aditiva ou multiplicativa) pelo mesmo fator:

$$
\hat{p}^{*}=k \hat{p} \Rightarrow I O H^{*}=(k \hat{p})(1-D)=k I O H
$$

b) sensibilidade para melhoria de Pareto: se a cobertura de um grupo aumenta sem diminuir a taxa de cobertura dos demais grupos o $\mathrm{IOH}$ também aumenta;

c) sensibilidade à redistribuição: se a taxa de cobertura de um grupo vulnerável aumenta mantendo a taxa de cobertura total constante, $\mathrm{o} \mathrm{IOH}$ também aumenta.

As mudanças do IOH ao longo do tempo (decomposição dinâmica) podem ser decompostas em dois componentes, segundo Barros et al. (2009): 
a) efeito distribuição $(\Delta D)$ : se refere à contribuição nas mudanças na distribuição das circunstâncias para a mudança do $\mathrm{IOH}$;

b) efeito escala $(\Delta \hat{p})$ : se refere à contribuição de uma variação proporcional na taxa de cobertura de todos os grupos.

Neste artigo, em que se calcula o IOH para 2003 (antes das ações afirmativas e primeiro ano em que a Pnad coleta a dependência administrativa da instituição de ensino) e para 2013 (dez anos após a implementação, ano mais recente disponível), a mudança temporal no $\mathrm{IOH}$ pode ser decomposta da seguinte forma:

$$
\Delta_{2013,2003}=I O H_{2013}-I O H_{2003}=\Delta \hat{p}+\Delta D
$$

onde o efeito escala e o efeito distribuição são definidos como segue:

$$
\begin{aligned}
& \Delta \hat{p}=\hat{p}_{2013}\left(1-D_{2013}\right)-\hat{p}_{2003}\left(1-D_{2003}\right) \\
& \Delta D=\hat{p}_{2013}\left(1-D_{2013}\right)-\hat{p}_{2013}\left(1-D_{2003}\right)
\end{aligned}
$$

Outra propriedade do índice $\mathrm{D}$, e por consequência do $\mathrm{IOH}$, é que ele é uma função do conjunto de circunstâncias consideradas, mas, claramente, do número de grupos de circunstâncias consideradas. Mais formalmente, considere o índice de dissimilaridade $\mathrm{D}$ calculado a partir do vetor de circunstâncias $x: D=D(x)$. Se mais circunstâncias são adicionadas, por exemplo, vetor $z$, o índice de dissimilaridade para uma oportunidade irá aumentar, ou seja:

$$
D(x) \leq D(x, z)
$$

O resultado acima significa que o índice $\mathrm{D}$ não pode ser menor, mesmo que circunstâncias em falta são adicionadas ao conjunto inicial de circunstâncias, isto é, o índice D será sempre um limite inferior do nível de dissimilaridade que se poderia obter no caso da perfeita observação das circunstâncias. A consequência dessa propriedade é que o índice $\mathrm{IOH}$, assim como qualquer outra medida de igualdade de oportunidades, subestima o grau de desigualdade de oportunidade e que a presente injustiça no acesso ao bem e serviço em questão pode ser maior do que a detectada pelo índice $\mathrm{IOH}$.

Vega et al. (2010) fazem uma ressalva ao IOH: não se trata de uma medida direta da desigualdade de oportunidade, mas uma medida que revela como as oportunidades em questão estão disponíveis e são alocadas numa sociedade com base no princípio da igualdade. Peragine (2011) também apresenta algumas reticências sobre a consistência do índice IOH com a teoria da igualdade de oportunidades, mas elogia o índice por resumir em uma única medida a extensão das oportunidades agregadas para determinado país como avaliação de justiça em termos de como as oportunidades são distribuídas.

\subsection{A contribuição de cada circunstância na desigualdade: a decomposição de Shapley}

Políticas de ação afirmativa (cotas ou bônus; "raciais" ou "sociais") têm sido implementadas no Brasil nos últimos dez anos com o objetivo de reduzir a desigualdade de oportunidades, por meio do aumento da probabilidade de acesso de grupos desfavorecidos ao ensino superior. Em abril de 2012, o STF 
declarou constitucional a reserva de vagas no ensino superior para afrodescendentes. Nesta seção, vamos apresentar a metolodogia que mensura a contribuição da cor/raça e outras características circunstanciais na desigualdade de oportunidades no acesso ao ensino superior.

Segundo Litchfield (1999), a técnica de decomposição de índices de desigualdade foi iniciada por Bourguignom (1979), sendo seguido por Cowell (1980) e Shorrocks (1980).

Existem três técnicas de decomposição:

a) Por subgrupos da população: o objetivo desta decomposição é separar a desigualdade total na distribuição entre grupos (Ib) e intra-grupos (Iw). Essa técnica de decomposição foi aplicada por Dill \& Gonçalves (2012) ao índice de Dissimilaridade D e ao IOH no acesso a serviços como energia elétrica, água limpa, saneamento e escola.

b) Decomposição dinâmica: considera mudanças no nível de desigualdade ao longo do tempo e as classifica em efeito distribuição e efeito escala. Foi essa a utilizada por Barros et al. (2009).

c) Decomposição por fator: considera as fontes e/ou fatores que determinam uma variável e mensura a contribuição de cada uma delas. Foi a escolhida por Hoyos \& Narayan (2012) na decomposição do IOH entre crianças para examinar o quanto o gênero contribui para a desigualdade no acesso aos serviços essenciais de frequência escolar e vacinação.

Neste artigo, optou-se pela terceira técnica de decomposição porque, segundo Shorrocks (1999), esse procedimento pode ser utilizado sempre que se deseje avaliar a importância relativa das variáveis circunstanciais no índice de desigualdade, que é o que se deseja neste estudo. Cabe ressaltar que, seguindo a literatura, decompõe-se somente o componente de desigualdade (D) do índice composto (IOH), e não o índice em si. Isto nos parece fazer sentido, pois o foco central dessa etapa de nosso estudo é avaliar a contribuição das diferentes circunstâncias para a parcela do $\mathrm{IOH}$ referente à desigualdade de oportunidade (intergrupos) na probabilidade de ingresso no ensino superior e não à carência de oportunidades em geral (válida para todos os grupos e expressa por $\hat{p}$ ).

Essa decomposição por fator teve originalmente como inspiração a composição da renda total de um indivíduo, geralmente composta por mais de uma fonte: rendimentos do trabalho, rendimentos de capital, transferências públicas e privadas etc. Seguindo esse exemplo, vamos definir o vetor total de rendas $y$ de uma população de tamanho $\mathrm{n}$ como a soma das rendas $y_{1}, y_{2}, \ldots, y_{n}$ onde $n$ é o tamanho da população. Seja $I(y)$ uma estimativa da desigualdade na distribuição da renda. Uma regra natural de decomposição permite descrever o índice de desigualdade como uma soma ponderada da renda, de acordo com Shorrocks (1982):

$$
I(y)=\sum_{i=1}^{n} a_{i}(y) y_{i}
$$

onde $a_{i}$ é o peso, $y_{i}$ é a renda, $i$ é indivíduo.

Sob essa estrutura, a contribuição proporcional ou relativa da fonte ou fator $k\left(s^{k}\right)$ na desigualdade total será calculada por: 


$$
s^{k}=\frac{s^{k}}{I(y)}=\frac{\sum_{i=1}^{n} a_{i}(y) y_{i}^{k}}{\sum_{i=1}^{n} a_{i}(y) y_{i}}
$$

onde $S^{k}$ é a contribuição absoluta.

Um resultado imediato da razão (10) é que $\sum_{k} s^{k}=1$. Para exemplificar, no caso do índice de Gini $\left(I_{\text {Gini }}\right)$ teremos a contribuição relativa do fator $k$ medida por $\left(s_{G i n i}^{k}\right)$ e calculada por:

$$
s_{\text {Gini }}^{k}=\frac{s_{\text {Gini }}^{k}}{I_{\text {Gini }}}=\frac{\sum_{i=1}^{n}\left(i-\frac{n+1}{2}\right) y_{i}^{k}}{\sum_{i=1}^{n}\left(i-\frac{n+1}{2}\right) y_{i}}
$$

De acordo com Sastre \& Trannoy (2002), a contribuição absoluta ${ }^{4}$ da fonte $k$ de acordo com a decomposição de Shapley por fator é dada por:

$$
s^{k}=\sum \frac{(s-1) !(j-s) !}{j !}[I(y(S))-I(y(S-\{k\}))]
$$

Traduzindo a contribuição absoluta da um fator $k$ de um índice de desigualdade $I(y)$ para a circunstância A de um índice de Dissimilaridade $\mathrm{D}(\mathrm{S})$, de acordo com Hoyos \& Narayan (2012):

$$
S^{A}=\sum_{S C\{A\}} \frac{(s-1) !(c-s) !}{c !}[D(S\{A\})-D(S)]
$$

onde:

$C$ é o conjunto de todas as circunstâncias, que contém $c$ circunstâncias;

$S$ é o subconjunto de $C$ que contém s circunstâncias;

$D(S U A)$ é o índice de dissimilaridade calculado no conjunto de circunstância $S$ e $A$;

$D(S)$ é o índice de dissimilaridade calculado com o conjunto de circunstâncias $\mathrm{S}$.

Para ilustrar melhor a equação (13) suponha que o índice de dissimilaridade é calculado usando três circunstâncias: $C_{1}, C_{2}$ e $C_{3}$. Dado que as circunstâncias são correlacionadas entre si, o impacto marginal dependerá que qual conjunto pré-existente de circunstâncias $C_{1}$ é adicionado: se $C_{1}$ é adicionado ao conjunto $\left\{C_{2}, C_{3}\right\} ;\left\{C_{2}\right\}$ ou $\left\{C_{3}\right\}$. Portanto, o impacto da adição da circunstância $C_{1}$ será dado por:

$$
\begin{aligned}
S^{1}= & \frac{2}{6}\left[D\left(C_{1}, C_{2}, C_{3}\right)-D\left(C_{2}, C_{3}\right)\right]+\frac{1}{6}\left[D\left(C_{1}, C_{2}\right)-D\left(C_{2}\right)\right]+ \\
& \frac{1}{6}\left[D\left(C_{1}, C_{3}\right)-D\left(C_{3}\right)\right]+\frac{2}{6}\left[D\left(C_{1}\right)-0\right]
\end{aligned}
$$

A contribuição relativa da circunstância $C_{1}$ de acordo com a decomposição de Shapley por fator será:

$$
s_{D-\text { indice }}^{1}=\frac{S^{1}}{D}
$$

onde D é o índice de dissimilaridade.

\footnotetext{
${ }^{4} \mathrm{~A}$ contribuição absoluta da fonte $\mathrm{k}$ também pode ser escrita em termos de variâncias conforme discussão apresentada em Ferreira \& Gignoux (2014).
} 


\section{Dados}

A base de dados selecionada para a mensuração da desigualdade de oportunidades no acesso ao ensino superior foi a Pesquisa Nacional por Amostra de Domicílios (Pnad) do IBGE. Dois motivos justificam essa escolha: primeiro, por ser uma pesquisa domiciliar de abrangência nacional e de periodicidade anual; segundo por investigar simultaneamente diversas características da população tais como educação, trabalho, rendimento e habitação, além de migração, fecundidade e características gerais dos domicílios.

O ano de 2013 foi selecionado por ser o ano mais recente disponível da Pnad. Escolhemos o ano de 2003 para definirmos um período exato de uma década entre os dois pontos de análise, por já haver informação do tipo de escola ou instituição de ensino que o aluno estava cursando (se pública ou privada) e também por coincidir temporalmente com o advento das políticas de ação afirmativa no ingresso ao ensino superior. No Brasil, as cotas foram instituídas pela primeira vez em 2001, na Universidade Estadual do Rio de Janeiro (UERJ) mas foram implementadas em 2003.

Como o nosso objeto de estudo são fatores relacionados ao acesso ao ensino superior, foram utilizados os seguintes filtros:

- Pessoas que moram em regiões urbanas;

- Que possuem entre 11 e 14 anos de estudo, isto é, que possuem o ensino médio completo como nível de instrução mais alto alcançado. Em 2013 tínhamos 44,9 milhões nesta situação escolar (26,3\% do total da população urbana).

- Entre 17 e 29 anos de idade, o que representa 73,4\% dos matriculados no ensino superior em 2013. Segundo o Mec/Inep, a faixa etária adequada/correta para se cursar o ensino superior no Brasil é entre 18 e 24 anos. Decidimos expandir essa faixa etária por causa do atraso escolar no ensino fundamental e médio e do grande estoque de pessoas sem ensino superior no Brasil. Outro motivo para a expansão da faixa etária é para a inclusão da idade média dos estudantes do ensino superior: 26,4 anos em 2013.

- Que são filhos na unidade domiciliar. Tivemos que usar esse filtro para poder capturar a instrução do chefe do domicílio na base de dados da Pnad. Outra justificativa é que, sendo filho na unidade domiciliar, o indivíduo não tem a obrigação de sustentar uma família e por isso tem mais opção entre escolher cursar uma universidade ou entrar no mercado de trabalho. Como o nosso objetivo neste capítulo é analisar o acesso ao ensino superior da demanda potencial, achamos que os filhos na unidade domiciliar pertencem a esse grupo. ${ }^{5}$ São filhos $54,0 \%$ das pessoas urbanas entre 17 e 29 anos de idade que possuem ensino médio completo.

As pessoas com características diferentes das citadas acima foram eliminadas da base de dados. A base de dados (ponderada) em 2003 totalizou 8,1

\footnotetext{
${ }^{5}$ Os dados da Pnad de 2013 comprovam esta hipótese. Entre as pessoas urbanas, de 17 a 29 anos de idade que estão matriculadas no ensino superior, $68,4 \%$ são filhos na unidade domiciliar; $11,2 \%$ são as pessoas de referência, $12,9 \%$ são outro parente e $7,5 \%$ são cônjuges.
} 
milhões de pessoas e 9,87 milhões de pessoas em 2013. Com a aplicação dos filtros acima, acreditamos que estamos tratando da demanda potencial ao acesso ao ensino superior no Brasil.

Segundo Hoyos \& Narayan (2012), para calcular o IOH para oportunidades de educação e saúde, além de uma pesquisa domiciliar (que é o caso da Pnad), é apropriado ter um conjunto mínimo de informações a nível individual, como gênero, localização (urbano/rural ou reginais), características dos pais, alguma medida do status socioeconômico do domicílio (rendimento, consumo ou riqueza). As características das pessoas consideradas como circunstâncias para analisar a probabilidade de acesso ao ensino superior foram:

- Gênero (duas categorias), medida por uma variável binária: 1 se mulher e 0 se homem;

- Etnia (duas categorias), medida por uma variável binária: 1 se branco ou amarelo e 0 se negro (preto, pardo ou mulato) ou indígena;

- Local de residência (cinco categorias), medida por quatro variáveis binárias regionais, com a região Sudeste como categoria base para analisar o efeito da oferta do ensino superior na concorrência de ingresso nos cursos;

- Nível de educação do chefe do domicílio (três categorias), medida por duas variáveis binárias, tendo ensino fundamental como categoria base como proxy para a origem familiar e background cultural da família.

- Grupo de riqueza da familiar que o indivíduo pertence, medido pelo rendimento domiciliar per capita (duas categorias): até 1,5 salários-mínimos ou mais de 1,5 salários-mínimos. Essa variável indica o status social ou a riqueza do domicílio. Foi medida com 1,5 salários mínimos porque esse é o critério utilizado para os beneficiados das ações afirmativas nas universidades federais e estaduais e também pelo programa Universidade para Todos (ProUni) para as instituições privadas do ensino superior.

Essas características pessoais consideradas como circunstâncias não são as únicas possíveis. Mas são as que estão disponíveis na base de dados utilizada. Por isso, no cálculo do índice de oportunidades humanas, temos a consciência de que se trata de um "lower bound", ou seja, de uma cota inferior da medida dado o número limitado de circunstâncias utilizadas.

A Tabela 1 apresenta um breve perfil do grupo aqui denominado "demanda potencial ao ensino superior", segundo suas circunstâncias, nos últimos 10 anos. A demanda potencial ao ensino superior aumentou 21,8\% no período e o número de matriculados entre 2003 e 2013 aumentou 33,9\%. Apenas $28,9 \%$ da demanda potencial ao ensino superior estavam matriculados em 2003 e este número aumentou em 2013 para 31,7\% da demanda. Com relação à cor/raça do indivíduo, a demanda potencial ao ensino superior dos negros aumentou $60 \%$ entre 2003 e 2013 e a matrícula no ensino superior deste grupo duplicou, passando de 512 mil pessoas em 2003 para 1 milhão de pessoas em 2013.

Para fins comparativos, nos Estados Unidos, que possuem ações afirmativas para minorias há 30 anos, apenas $5,75 \%$ dos candidatos a uma vaga nas faculdades e universidades mais seletivas eram negros em 1989 (Bowen \& Bok 
2004). O Brasil que possui uma proporção da população negra muito maior, representando 47\% da demanda potencial em 2013 (4,6 milhões sobre 9,8 milhões), instituiu reserva de vagas para os negros em todas as universidades federais apenas em 2012 com a "Leis das Cotas".

Com relação à origem familiar, o volume da demanda potencial com chefe do domicílio com ensino médio como nível mais alto de educação aumentou $70 \%$ entre 2003 e 2013 e a matrícula deste grupo no ensino superior aumentou 40\%, passando de 817 mil pessoas em 2003 para um milhão em 2011. Entretanto, em termos relativos, a maior incidência de matrícula no ensino superior é observada em filhos com chefe com ensino superior: $69,6 \%$ da demanda potencial estava matriculada no ensino superior em 2003 e 59,1\% desse grupo em 2013 em comparação aos filhos com chefe com ensino médio: 42,8\% em 2003 e 36,5\% em 2013. Para captar o efeito dos recursos do domicílio disponíveis para o acesso ao ensino superior, apesar do aumento expressivo da demanda potencial com até 1,5 salário mínimo de renda domiciliar per capita no período, apenas $23,3 \%$ deste grupo garantiu sua matrícula no ensino superior em 2013.

Em suma, as categorias de circunstâncias que mais evoluíram no período entre 2003 e 2013 em termos de demanda e número de matriculas no ensino superior foram os pretos/pardos/mulatos, os residentes da região Norte, as pessoas com pai com ensino médio completo e também as pessoas com renda domiciliar per capita de até 1,5 sm. Mas o ingresso no ensino superior é maior, em termos relativos, para os indivíduos com renda domiciliar per capita superior a $1,5 \mathrm{sm}$ e com pai com ensino superior, indicando a forte relação entre matrícula no ensino superior com pai muito instruído e com alto nível social.

A Tabela 2 apresenta um perfil dos ingressantes do ensino superior público e privado entre a demanda potencial. Nos 10 últimos anos de ação afirmativa (cotas, bônus, ProUni), a taxa de ingresso da demanda potencial nas instituições de ensino superior (IES) públicas aumentou de 9,4\% em 2003 para 10,9\% em 2013. A taxa de ingresso nas IES privadas aumentou de $23,2 \%$ em 2003 para $25,5 \%$ em 2013. As categorias com maior taxa de ingresso são as mulheres, os brancos, pai com educação superior e domicílios com renda alta. Entretanto, a taxa de ingresso dos negros aumentou no período analisado, tanto nas IES públicas quanto nas privadas. A taxa de ingresso dos filhos cujo pai possui pelo menos o ensino médio reduziu entre 2003 e 2013 nas instituições públicas e privadas.

\section{Resultados}

O primeiro passo para o cálculo do IOH é obter as probabilidades condicionais de acesso à oportunidade em questão, que neste trabalho consiste em ingressar numa instituição de educação superior (IES) com base nas suas circunstâncias. Como o nível de concorrência entre as IES públicas é muito maior do que nas IES privadas, gostaríamos de estimar duas regressões logísticas separadas: uma para as IES públicas e outra para as privadas. Os microdados da Pnad de 2003 e 2013 trazem essa informação da dependência administrativa da escola/IES que a pessoa está cursando. ${ }^{6}$

\footnotetext{
${ }^{6}$ A Pnad é uma pesquisa que utiliza um plano amostral complexo e isso implica a necessidade de alguns procedimentos na estimação de modelos estatísticos. Por isso, a estimação dos modelos econométricos foi feita por meio de comando de pacote estatístico que leva em conta a estrutura
} 
Desigualdade de oportunidades no acesso ao Ensino Superior no Brasil: uma comparação entre 2003 e 2013385

Tabela 1: Perfil da demanda potencial ao ensino superior - Brasil (2003 e 2013)

\begin{tabular}{|c|c|c|c|c|c|c|c|}
\hline \multirow{4}{*}{$\begin{array}{l}\text { Circunstân- } \\
\text { cias }\end{array}$} & \multirow{4}{*}{ Categoria } & \multicolumn{6}{|c|}{ Demanda Potencial ao Ensino Superior, em 1.000 pessoas } \\
\hline & & \multicolumn{3}{|c|}{2003} & \multicolumn{3}{|c|}{2013} \\
\hline & & \multirow{2}{*}{ Total } & \multicolumn{2}{|c|}{ Matriculados IES } & \multirow{2}{*}{ Total } & \multicolumn{2}{|c|}{ Matriculados IES } \\
\hline & & & $\mathrm{N}^{\mathrm{o}}$ & $\%$ & & $\mathrm{~N}^{\mathrm{o}}$ & $\%$ \\
\hline Total & & 8117 & 2342 & 28,9 & 9890 & 3135 & 31,7 \\
\hline \multirow{2}{*}{ Sexo } & Homem & 3421 & 1062 & 31,0 & 5007 & 1438 & 28,7 \\
\hline & Mulher & 3817 & 1281 & 33,6 & 4873 & 1697 & 34,8 \\
\hline \multirow{2}{*}{ Etnia } & $\begin{array}{l}\text { Branco e Ama- } \\
\text { relo }\end{array}$ & 5196 & 1830 & 35,2 & 5224 & 1971 & 37,7 \\
\hline & $\begin{array}{l}\text { Preto, Pardo e } \\
\text { Mulato }\end{array}$ & 2920 & 512 & 17,5 & 4656 & 1164 & 25,0 \\
\hline \multirow{5}{*}{$\begin{array}{l}\text { Região de } \\
\text { Residência }\end{array}$} & Norte & 401 & 92 & 22,9 & 663 & 190 & 28,7 \\
\hline & Nordeste & 1506 & 375 & 24,9 & 2189 & 673 & 30,8 \\
\hline & Sudeste & 4540 & 1249 & 27,5 & 4990 & 1440 & 28,8 \\
\hline & Sul & 1157 & 442 & 38,2 & 1308 & 516 & 39,5 \\
\hline & Centro-Oeste & 513 & 183 & 35,7 & 730 & 315 & 43,2 \\
\hline Escolaridade & $\begin{array}{l}\text { Até Funda- } \\
\text { mental }\end{array}$ & 5275 & 882 & 16,7 & 5165 & 1066 & 20,6 \\
\hline \multirow{2}{*}{ Do chefe } & Médio & 1909 & 817 & 42,8 & 3156 & 1151 & 36,5 \\
\hline & Superior & 922 & 642 & 69,6 & 1548 & 915 & 59,1 \\
\hline Renda Dom. & Até 1,5 sm & 3835 & 480 & 12,5 & 6008 & 1400 & 23,3 \\
\hline Per capita & $\begin{array}{l}\text { Mais de 1,5 } \\
\text { sm }\end{array}$ & 4032 & 1758 & 43,6 & 3140 & 1486 & 47,3 \\
\hline
\end{tabular}

Fonte: IBGE, Microdados das Pnads 2003 e 2013.

${ }^{1}$ Pessoas que vivem em áreas urbanas, entre 11 e 14 anos de estudo (ensino médio completo como nível de instrução mais alto alcançado), entre 17 e 29 anos de idade e filho como posição no domicílio.

${ }^{2} \mathrm{O}$ salário mínimo nominal vigente na época da pesquisa (setembro) era: 240 reais em 2003 e 678 reais em 2013. Os pontos de corte (1,5 sm) foram: 360 reais em 2003 e 1017 reais em 2013.

Precisamos estimar um modelo em que $Y$ é a variável dependente binária, que assume o valor 1 se o indivíduo teve acesso à oportunidade que é ingressar no ensino superior e 0 se não teve. Os dois modelos mais comuns para estimar variável dependente binária são o probit binário e o logit binário. $\mathrm{O}$ modelo logit usa a função logística acumulada e o modelo probit usa a função de distribuição acumulada da normal. Graficamente, a função logística tem as caudas ligeiramente mais achatadas, ou seja, a função acumulada da normal se aproxima do eixo mais rapidamente do que a curva logística. Não há razão técnica para se preferir um a outro. Neste artigo, optou-se pelo modelo logit. A equação 16 apresenta o modelo logit na forma linear nos parâmetros. A matriz $X$ é formada pelos vetores $x_{j}$ que representam as circunstâncias disponíveis na Pnad e utilizada na pesquisa e $\beta_{j}$ representa os $k+1$ parâmetros que serão estimados pelo modelo. O $\pi\left(x_{i}\right)$ é uma simplificação da notação, que representa a média condicional de $Y$ dado $X$ quando a distribuição logística é utilizada. 
Tabela 2: Perfil da dos ingressantes do ensino superior entre a demanda potencial Brasil (2003 e 2013)

\begin{tabular}{|c|c|c|c|c|c|c|c|c|c|}
\hline \multirow[t]{3}{*}{ Variáveis } & \multirow[t]{3}{*}{ Categorias } & \multicolumn{4}{|c|}{ IES PÚBLICAS } & \multicolumn{4}{|c|}{ IES PRIVADAS } \\
\hline & & \multicolumn{2}{|c|}{2003} & \multicolumn{2}{|c|}{2013} & \multicolumn{2}{|c|}{2003} & \multicolumn{2}{|c|}{2013} \\
\hline & & Não Ingr. & Ingr. & Não Ingr. & Ingr. & Não Ingr. & Ingr. & Não Ingr. & Ingr. \\
\hline Total & & 90,6 & 9,4 & 89,1 & 10,9 & 76,8 & 23,2 & 74,5 & 25,5 \\
\hline \multirow{2}{*}{ Sexo } & Masculino & 91,0 & 9,0 & 90,0 & 10,0 & 78,5 & 21,5 & 77,4 & 22,6 \\
\hline & Feminino & 90,1 & 9,9 & 88,1 & 11,9 & 75,2 & 24,8 & 71,5 & 28,5 \\
\hline \multirow{2}{*}{ Etnia } & branco / amarela & 88,9 & 11,1 & 86,5 & 13,5 & 70,5 & 29,5 & 69,0 & 31,0 \\
\hline & preta / parda / indígena & 93,0 & 7,0 & 91,7 & 8,3 & 87,9 & 12,1 & 80,4 & 19,6 \\
\hline \multirow{5}{*}{ Região } & Norte & 88,6 & 11,4 & 87,3 & 12,7 & 85,6 & 14,4 & 79,6 & 20,4 \\
\hline & Nordeste & 86,5 & 13,5 & 85,9 & 14,1 & 85,0 & 15,0 & 78,1 & 21,9 \\
\hline & Sudeste & 93,3 & 6,7 & 92,3 & 7,7 & 76,4 & 23,6 & 75,6 & 24,4 \\
\hline & Sul & 87,3 & 12,7 & 86,3 & 13,7 & 67,9 & 32,1 & 66,9 & 33,1 \\
\hline & Centro-oeste & 88,0 & 12,0 & 83,0 & 17,0 & 70,5 & 29,5 & 64,3 & 35,7 \\
\hline \multirow{3}{*}{ Escol_chefe } & Até EFund. & 95,3 & 4,7 & 94,4 & 5,6 & 86,8 & 13,2 & 83,3 & 16,7 \\
\hline & EMédio & 83,6 & 16,4 & 86,8 & 13,2 & 64,4 & 35,6 & 70,3 & 29,7 \\
\hline & ESup & 62,3 & 37,7 & 69,6 & 30,4 & 37,3 & 62,7 & 49,8 & 50,2 \\
\hline \multirow{2}{*}{ Renda Dom. } & Até 1,5 SM & 94,6 & 5,4 & 91,8 & 8,2 & 92,1 & 7,9 & 82,3 & 17,7 \\
\hline & Acima de $1,5 \mathrm{SM}$ & 85,6 & 14,4 & 82,4 & 17,6 & 62,3 & 37,7 & 59,3 & 40,7 \\
\hline
\end{tabular}

Fonte: IBGE, Pnads 2003 e 2013. Tabulações dos autores.

${ }^{1}$ Pessoas de 17 a 29 anos de idade, residentes em áreas urbanas, com ensino médio completo como nível de instrução mais alto alcançado e filho na posição do domicílio. 


$$
\ln \left(\frac{\pi\left(x_{i}\right)}{1-\pi\left(x_{i}\right)}\right)=\ln \left(\frac{P\left(Y_{i}=1 \mid X=\left(x_{1}, x_{2}, \ldots, x_{k}\right)\right)}{P\left(Y_{i}=0 \mid X=\left(x_{1}, x_{2}, \ldots, x_{k}\right)\right)}\right)=\beta_{0}+\sum_{j=1}^{k} \beta_{j} x_{i, j}
$$

onde $\pi\left(x_{i}\right)=E(Y \mid X)=\frac{\epsilon^{\beta_{0}+\sum \beta_{j} x_{i j}}}{1+\epsilon^{\beta_{0}+\sum b_{j} x_{i j}}}$

Essas estimações estão sujeitas a viés de simultaneidade - por exemplo, entre ingresso ou não no ensino superior e renda - , o que pode tornar questionável o processo de inferência e os resultados (Cruz \& Moreira 2005). Diante da impossibilidade de se usarem variáveis instrumentais, ou outra técnica, para resolver o problema, optou-se por se apresentar os resultados de qualquer forma, fazendo-se a ressalva de que não há, na estimação dessas equações, nenhuma pretensão de estabelecimento de causalidade. Isto significa que, em havendo disponibilidade de dados que permitam corrigir o problema, é desejável que resultados de estudos futuros sejam comparados aos deste trabalho.

A Tabela 3 apresenta os coeficientes estimados $(\beta)$, o erro padrão $E p(\beta)$ e a razão de chances $\exp (\beta)$. Como o modelo de regressão é o logit, podemos interpretar seus coeficientes por meio da razão de chances, $\exp (\beta)$. Observese que a circunstância que obteve coeficiente com maior valor para o acesso aos cursos de graduação no Brasil em todos os anos foi a chefe e superior, que significa que domicílio com chefe com ensino superior possui uma chance de ingressar é 6,3 vezes maior que a de não ingressar em 2003 e 3,82 vezes em 2013. Separando o ingresso entre as instituições públicas e privadas em 2003, a variável que mais contribuiu para o ingresso na instituição pública foi o fato de o chefe do domicílio ter instrução superior, apesar de estar reduzindo sua participação: a chance de um filho(a) cujo pai possui instrução superior ingressar era de 8,67 em 2003 e reduziu para 5,54 em 2013. Entre as instituições privadas, além do nível de instrução do pai, a renda domiciliar também possui uma alta razão de chance para o ingresso: 4,17 em 2003 e 2,34 em 2013.

A Tabela 3 também apresenta algumas estatísticas dos testes de validação do modelo. A rejeição da hipótese nula de que todos os coeficientes (exceto a constante) são conjuntamente iguais a zero (teste de Qui-Quadrado) possui a interpretação análoga ao teste global $\mathrm{F}$ do modelo de regressão linear múltiplo: que pelo menos um dos coeficientes é diferente de zero. A proporção de $Y$ corretamente predito é superior a $70 \%$ em todos os modelos estimados. O $R^{2}$ de McFadden, que é um índice da razão de verossimilhança, denotado por $R^{2}=1-\frac{\ln L \text { (Modelocompleto })}{\ln L \text { (ModeloIntercepto })}$, também foi calculado para todos os modelos. Com todas essas estatísticas, podemos concluir que os modelos estimados passaram pelo teste de validação.

Com os coeficientes estimados, pode-se obter para cada indivíduo da amostra sua probabilidade prevista de acesso ao ensino superior $\hat{p}_{i}$ :

$$
\hat{p}_{i}=\frac{\exp \left(\hat{\beta}_{0}+\sum_{j=1}^{k} \hat{\beta}_{j} x_{i, j}\right)}{1+\exp \left(\hat{\beta}_{0}+\sum_{j=1}^{k} \hat{\beta}_{j} x_{i, j}\right)}
$$

Usando as probabilidades previstas na equação (17) e os pesos amostrais $w$, calculamos a taxa média de acesso ao ensino superior $\bar{p}$, também conhecida como a taxa global de cobertura prevista: 
Tabela 3: Resultados da estimação do Modelo Logit, por categoria administrativa da IES — Brasil (2003 e 2013)

\begin{tabular}{|c|c|c|c|c|c|c|c|c|c|c|c|c|c|c|c|c|c|c|}
\hline \multirow{3}{*}{$\begin{array}{l}\text { Variáveis / } \\
\text { Circunstâncias }\end{array}$} & \multicolumn{6}{|c|}{ IES Total } & \multicolumn{6}{|c|}{ IES Públicas } & \multicolumn{6}{|c|}{ IES Privadas } \\
\hline & \multicolumn{3}{|c|}{2003} & \multicolumn{3}{|c|}{2013} & \multicolumn{3}{|c|}{2003} & \multicolumn{3}{|c|}{2013} & \multicolumn{3}{|c|}{2003} & \multicolumn{3}{|c|}{2013} \\
\hline & $\beta$ & $\mathrm{EP}(\beta)$ & $\operatorname{Exp}(\beta)$ & $\beta$ & $\operatorname{EP}(\beta)$ & $\operatorname{Exp}(\beta)$ & $\beta$ & $\mathrm{EP}(\beta)$ & $\operatorname{Exp}(\beta)$ & $\beta$ & $\operatorname{EP}(\beta)$ & $\operatorname{Exp}(\beta)$ & $\beta$ & $\mathrm{EP}(\beta)$ & $\operatorname{Exp}(\beta)$ & $\beta$ & $\mathrm{EP}(\beta)$ & $\operatorname{Exp}(\beta)$ \\
\hline Mulher & 0,38 & 0,02 & 1,46 & 0,45 & 0,02 & 1,57 & 0,23 & 0,03 & 1,26 & 0,29 & 0,03 & 1,34 & 0,44 & 0,02 & 1,55 & 0,50 & 0,02 & 1,65 \\
\hline Branco / Amarelo & 0,53 & 0,02 & 1,69 & 0,34 & 0,02 & 1,41 & 0,42 & 0,04 & 1,52 & 0,41 & 0,03 & 1,51 & 0,58 & 0,03 & 1,78 & 0,32 & 0,02 & 1,38 \\
\hline Região Norte & 0,25 & 0,05 & 1,29 & 0,20 & 0,03 & 1,22 & 1,02 & 0,06 & 2,78 & 0,81 & 0,05 & 2,25 & $-0,11$ & 0,06 & 0,90 & $-0,03$ & 0,04 & 0,97 \\
\hline Região Nordeste & 0,36 & 0,03 & 1,44 & 0,34 & 0,02 & 1,41 & 1,18 & 0,04 & 3,24 & 0,98 & 0,03 & 2,65 & $-0,05$ & 0,03 & 0,95 & 0,12 & 0,02 & 1,12 \\
\hline Região Sul & 0,46 & 0,03 & 1,59 & 0,30 & 0,02 & 1,35 & 0,65 & 0,04 & 1,92 & 0,50 & 0,04 & 1,66 & 0,40 & 0,03 & 1,50 & 0,24 & 0,03 & 1,27 \\
\hline Região C-Oeste & 0,47 & 0,04 & 1,59 & 0,63 & 0,03 & 1,87 & 0,72 & 0,06 & 2,06 & 0,89 & 0,05 & 2,43 & 0,40 & 0,04 & 1,49 & 0,55 & 0,03 & 1,73 \\
\hline Chefe_EMédio & 0,99 & 0,02 & 2,70 & 0,66 & 0,02 & 1,93 & 1,14 & 0,03 & 3,11 & 0,83 & 0,03 & 2,29 & 0,94 & 0,02 & 2,56 & 0,60 & 0,02 & 1,83 \\
\hline Chefe_ESuperior & 1,84 & 0,03 & 6,30 & 1,34 & 0,02 & 3,82 & 2,16 & 0,04 & 8,67 & 1,71 & 0,04 & 5,54 & 1,74 & 0,03 & 5,70 & 1,21 & 0,02 & 3,37 \\
\hline Renda_> 1,5 SM & 1,21 & 0,02 & 3,34 & 0,75 & 0,02 & 2,13 & 0,67 & 0,03 & 1,95 & 0,48 & 0,03 & 1,62 & 1,43 & 0,02 & 4,17 & 0,85 & 0,02 & 2,34 \\
\hline Constante & $-2,92$ & 0,03 & 0,05 & $-2,12$ & 0,02 & 0,12 & $-4,14$ & 0,05 & 0,02 & $-3,73$ & 0,04 & 0,02 & $-3,34$ & 0,03 & 0,04 & $-2,36$ & 0,02 & 0,09 \\
\hline $\begin{array}{l}\% \text { Y estimado cor- } \\
\text { retamente }\end{array}$ & & 76,92 & & & 72,12 & & & 90,79 & & & 89,20 & & & 79,88 & & & 75,82 & \\
\hline $\begin{array}{l}\text { Estatística de Qui- } \\
\text { Quadrado ( } 9 \mathrm{gl})\end{array}$ & & 17477,9 & & & 11638,6 & & & 5762,6 & & & 5188,4 & & & 15718,4 & & & 9403,8 & \\
\hline p-valor & & $<0,000$ & & & $<0,000$ & & & $<0,000$ & & & $<0,000$ & & & $<0,000$ & & & $<0,000$ & \\
\hline $\begin{array}{l}\text { McFadden's } \quad \mathrm{R} \\
\text { Square }\end{array}$ & & 0,1862 & & & 0,1023 & & & 0,1503 & & & 0,1078 & & & 0,2010 & & & 0,0993 & \\
\hline
\end{tabular}

Fonte: Fonte: Elaboração própria a partir dos microdados da Pnad.

Nota: $\beta=$ parâmetro estimado; $\operatorname{EP}(\beta)=$ erro-padrão, $\operatorname{Exp}(\beta)=$ razão de chances. 


$$
\bar{p}=\sum_{i=1}^{n} w_{i} \hat{p}_{i}
$$

Com o número de categorias em cada circunstância ( $\operatorname{sexo}=2$, etnia $=2$, região $=5$, educação do chefe $=3$, grupos de quintos de rendimento $=2$ ) podemos combinar todas essas categorias em 120 grupos $(2 \times 2 \times 5 \times 3 \times 2)$ e assim estimar a probabilidade média prevista de ingresso dos indivíduos ao ensino superior em cada grupo $k$.

\subsection{Grupos sociais "vulneráveis" no tocante ao ensino superior}

Os grupos cuja probabilidade média de ingresso $\left(p_{k}\right)$ é inferior à probabilidade média de acesso $(\bar{p})$ são chamados de grupos de "pessoas vulneráveis no que se refere ao acesso ao ensino superior". Ordenando as probabilidades de acesso de cada grupo do menor para o maior, obtemos as Figuras A.1 e A.2 (Apêndice).

O grupo mais vulnerável no acesso ao ensino superior público, isto é, com menor probabilidade de acesso, é formado por homens não brancos, residentes da região Sudeste, com pai com até ensino fundamental como nível de instrução e renda domiciliar alta. A probabilidade média de acesso desse grupo em 2003 era de 1,57\% e em 2013, 2,33\%. O grupo com maior probabilidade de acesso nas instituições públicas (menos vulnerável) era formado por mulheres brancas, residentes na região nordeste, com pai com nível de instrução superior e renda baixa. As probabilidades de acesso desse grupo em 2003 e 2013 são respectivamente $62,5 \%$ e $53,6 \%$.

Com relação às instituições privadas, o grupo mais vulnerável no acesso (menor probabilidade) é composto por homens, não brancos, residentes da região Norte, com pai com até ensino fundamental e renda alta. O grupo menos vulnerável é formado por mulheres brancas, residentes na região sudeste, com pai com educação superior e renda baixa. As probabilidades de acesso são respectivamente 77,7\% em 2003 e 74,5\% em 2013.

\section{2 Índice de igualdade de oportunidades ao acesso ao ensino superior}

Agora podemos calcular o índice de dissimilaridade (D) relativo ao acesso ao ensino superior, que mede qual proporção do total de oportunidades deveria ser realocada para restabelecer a igualdade de oportunidades. O cálculo do índice D é baseado nos grupos com oportunidade de acesso ao ensino superior, isto é, os "não vulneráveis" $\left(p_{k}>\bar{p}\right)$ :

$$
\begin{gathered}
D=\frac{1}{2 \bar{p}} \sum_{k-1}^{K} w_{k}\left(\bar{p}-p_{k}\right) \\
I O H=\bar{p}(1-D)
\end{gathered}
$$

Os componentes $\mathrm{D}$ e $\bar{p}$ foram combinados segundo a equação (20) para gerar o IOH (Tabela 4). O índice de dissimilaridade (D) em 2003 indica que, para alcançar a igualdade de oportunidades no acesso ao ensino superior, 15,5\% das pessoas deveriam ser realocadas - isto é, deveriam ceder seus lugares na universidade ou ocupar esses lugares cedidos. O índice de dissimilaridade de 2013 cai para 10,8\%, o que indica que houve realocação de oportunidade dos 
grupos "não vulneráveis" para os grupos "vulneráveis". A disponibilidade do ensino superior para a sociedade (taxa de cobertura) aumentou de 28,5\% em 2003 para $31,6 \%$ em 2013, e a desigualdade no acesso ao ensino superior reduziu-se, o que resulta em um IOH maior em 2013.

Tabela 4: IOH no acesso ao ensino superior e seus componentes - Brasil (2003 e 2013)

\begin{tabular}{lcccccc}
\hline Indicadores & \multicolumn{2}{c}{ Total } & \multicolumn{2}{c}{ Públicas } & \multicolumn{2}{c}{ Privadas } \\
\cline { 2 - 7 } & 2003 & 2013 & 2003 & 2013 & 2003 & 2013 \\
\hline Mínima & 0,051 & 0,107 & 0,015 & 0,023 & 0,031 & 0,084 \\
Máxima & 0,817 & 0,801 & 0,625 & 0,536 & 0,777 & 0,745 \\
Média & 0,285 & 0,316 & 0,113 & 0,121 & 0,237 & 0,261 \\
\hline $\mathrm{D}$ & 0,155 & 0,108 & 0,196 & 0,158 & 0,177 & 0,120 \\
\hline IOH & 0,240 & 0,281 & 0,091 & 0,102 & 0,195 & 0,230 \\
\hline Fonte: Elaboração própria a partir dos microdados da Pnad.
\end{tabular}

Entretanto, o $\mathrm{IOH}$ para o acesso ao ensino superior está muito longe da situação ideal $(I O H=1)$ que ocorre quando o acesso é universal $(\bar{p}=1)$ e não há desigualdade no acesso $\left(\bar{p}=p_{k} \Rightarrow D=0\right)$. O IOH calculado evidencia quão distante está o Brasil de um acesso amplo e igualitário ao ensino superior, indicando como as características pessoais impactam na probabilidade de ter acesso a este nível de ensino. Para se ter uma ideia dessa reduzida igualdade de oportunidades no acesso ao ensino superior comparado com outros níveis educacionais e serviços, vamos comparar o resultado encontrado aqui com o de Dill \& Gonçalves (2012), que utilizaram a Pnad e a mesma metodologia de Barros et al. (2009). Com relação ao componente educação, eles consideraram a probabilidade de se completar a sexta série na idade adequada. Observe que houve aumento de cobertura deste componente de 62,12\% em 1999 para 73,16\% em 2009 (Tabela 5). Também observaram uma redução na desigualdade no acesso a este componente educacional, o que resultou em um IOH maior em 2009, alcançando 0,6984. Entre os componentes analisados, o que alcançou maior $\mathrm{IOH}$ foi acesso à eletricidade no domicílio, que com uma cobertura de 98,22\% dos domicílios em 2009 e uma desigualdade no acesso a este serviço muito baixa $(1,18 \%)$, alcançou um $\mathrm{IOH}$ de $97,06 \%$, muito próximo de $100 \%$.

Tabela 5: IOH no acesso à educação básica, saneamento, água e energia e seus componentes — Brasil (1999 e 2009)

\begin{tabular}{llcccc}
\hline Ano & Indicadores & Educação & Saneamento & Água & Energia \\
\hline \multirow{2}{*}{1999} & Cobertura & 0,6212 & 0,4407 & 0,8042 & 0,9332 \\
& Dissimilaridade & 0,0895 & 0,2419 & 0,1118 & 0,0472 \\
& IOH & 0,5656 & 0,3341 & 0,7143 & 0,8892 \\
\hline \multirow{2}{*}{2009} & Cobertura & 0,7316 & 0,4926 & 0,8920 & 0,9822 \\
& Dissimilaridade & 0,0452 & 0,2021 & 0,0624 & 0,0118 \\
& IOH & 0,6984 & 0,3930 & 0,8364 & 0,9706 \\
\hline
\end{tabular}

Fonte: Dill \& Gonçalves (2012). Microdados da Pnad.

A mudança do $\mathrm{IOH}$ ao longo do tempo, isto é, de 2003 a 2013, também medido por $\Delta_{2013,2003}=I O H_{2013}-I O H_{2003}=0,041$, pode ser decomposta em 
dois componentes:

- Efeito escala, que se refere à contribuição de uma variação na taxa de cobertura e calculada por: $\Delta \bar{p}=\bar{p}_{2013}\left(1-D_{2013}\right)-\bar{p}_{2013}\left(1-D_{2003}\right)=0,026$.

- Efeito distribuição, que se refere à contribuição nas mudanças da distribuição das circunstâncias para mudanças no IOH: $\Delta D=\bar{p}_{2013}\left(1-D_{2013}\right)-$ $\bar{p}_{2013}\left(1-D_{2013}\right)=0,015$.

Observe-se que, no período de 2003 a 2013, o efeito escala foi maior que o efeito distribuição, indicando que as ações afirmativas (cotas, bônus, ProUni) tiveram maior contribuição na taxa de cobertura do ensino superior do que na distribuição das vagas segundo as circunstâncias consideradas.

Cabe ressaltar que os cálculos utilizados nesta seção possuem uma limitação: levam em consideração os filtros adotados, isto é, trata-se do acesso e da dissimilaridade da demanda potencial ao ensino superior, que foi definida como as pessoas urbanas de 17 a 29 anos de idade, que são filhos na unidade domiciliar. $\mathrm{O}$ avanço do ensino superior com relação às pessoas de 30 anos ou mais de idade não foi considerado nesse cálculo.

\subsection{A contribuição de cada circunstância: a decomposição por fatores de Shapley}

Conforme a Tabela 6, a variável cor/raça não é a circunstância com maior contribuição na desigualdade de oportunidades no acesso ao ensino superior, medido pelo índice de dissimilaridade $\mathrm{D}$, mas tem um efeito razoável que, se acumulado com as demais circunstâncias, pode ser decisivo para impedir o acesso à universidade. ${ }^{7}$ Em 2003, a variável cor/raça explicava 13,8\% do índice de D. Em 2013, esta circunstância aumentou sua participação para 14,7\% na desigualdade. As circunstâncias que mais contribuem para o acesso ao ensino superior no Brasil são as relacionadas ao background familiar, mensurada pela instrução do chefe do domicílio e também pela renda domiciliar per capita: em 2003 e em 2013 contribuíram com mais de 70\% do total de desigualdade. Note-se que a instrução do chefe do domicílio é a circunstância com maior contribuição ao acesso dos cursos das IES públicas e a renda domiciliar per capita é a circunstância com maior contribuição dentre as instituições privadas. Note-se também na Tabela 6 que houve uma redução da contribuição da instrução do chefe no acesso aos cursos de instituições públicas e um aumento na contribuição da cor/raça, talvez pelo fato da primeira não fazer parte do critério de concessão de bolsas do ProUni e das cotas e da segunda circunstância fazer parte.

Litchfield (1999) adverte que os resultados de qualquer decomposição devem ser discutidos e analisados como meramente descritivos porque a desigualdade é determinada por muitos fatores e em equilíbrio geral. Acrescentese que não há preocupação, nessa literatura, de se estabelecerem relações causais. Trata-se de correlações condicionais entre um conjunto de variáveis dependentes e uma variável de resposta.

\footnotetext{
${ }^{7}$ Vale notar que outras definições de grupos (ex. uma definição mais fina de cor/raça que a adotada aqui) poderiam conduzir a resultados diferentes dos apresentados nesta seção. Por isso, adota-se cautela nas interpretações.
} 
Tabela 6: Contribuição Relativa das Circunstâncias ao Acesso ao ensino superior, utilizando a decomposição por fator de Shappley - Brasil $(2003,2013)$

\begin{tabular}{lrrrrrr}
\hline \multirow{2}{*}{ Circunstância } & \multicolumn{2}{c}{ Todas as IES } & \multicolumn{2}{c}{ IES Públicas } & \multicolumn{2}{c}{ IES Privadas } \\
\cline { 2 - 7 } & 2003 & 2013 & 2003 & 2013 & 2003 & 2013 \\
\hline Gênero & 1,7 & 4,0 & 1,0 & 2,5 & 2,4 & 5,2 \\
Cor/Raça & 13,8 & 14,7 & 6,2 & 10,8 & 14,8 & 13,1 \\
Região & 3,7 & 8,2 & 11,3 & 17,3 & 5,5 & 6,9 \\
Instrução Chefe & 40,7 & 39,0 & 59,8 & 48,1 & 36,8 & 36,1 \\
Renda Domiciliar & 40,1 & 34,1 & 21,7 & 21,3 & 40,5 & 38,7 \\
Total & 100,0 & 100,0 & 100,0 & 100,0 & 100,0 & 100,0 \\
\hline
\end{tabular}

Fonte: IBGE, Pnad.

\section{Conclusões}

Apesar dos avanços no ensino fundamental e médio nas últimas décadas, e da ampliação de vagas no ensino superior, apenas $12 \%$ dos jovens em idade universitária estão cursando o ensino superior no Brasil. Na Argentina essa cobertura chega a $21 \%$, nos Estados Unidos a $65 \%$ e na Suécia a $70 \%$.

Neste estudo, a partir dos microdados mais recentes da Pnad disponíveis (2013) e dos dados de uma década anterior, antes das ações afirmativas no acesso ao ensino superior serem adotadas no Brasil (2003), traça-se um perfil dos grupos "vulneráveis" e "não vulneráveis" ao acesso ao ensino superior, considerando a demanda potencial ao acesso ao ensino superior.

Mensuraram-se também as desigualdades de oportunidades no acesso ao ensino superior no Brasil. O índice de dissimilaridade (D) em 2003 indica que $15,5 \%$ das oportunidades deveriam ser realocadas para restabelecer a igualdade. Já o mesmo índice em 2013 reduziu para 10,8\%, o que indica que houve realocação de oportunidade dos grupos "não vulneráveis" para os grupos "vulneráveis". Assim, a disponibilidade do ensino superior para a sociedade aumentou (de $28,5 \%$ para $31,6 \%$ ) e a desigualdade no acesso ao ensino superior caiu. Entretanto, o índice de oportunidades humanas ao acesso ao ensino superior no Brasil ( $\mathrm{IOH}=0,281 \mathrm{em} 2013)$ está muito longe da situação ideal $(I O H=1)$ que ocorre quando o acesso é universal $(\bar{p}=1)$ e não há desigualdade no acesso $(\mathrm{D}=0)$.

Utilizando a decomposição de Shapley por fatores, as circunstâncias que mais contribuem para a desigualdade de oportunidades no acesso ao ensino superior são: a instrução do chefe do domicílio e a renda domiciliar per capita, ou seja, o background cultural da família e o status econômico. Esses dois fatores conjuntamente explicavam $80,8 \%$ do índice de dissimilaridade (D) do acesso ao ensino superior em 2003; e 73,2\% do índice D em 2013. Nas instituições públicas, destaca-se a instrução do pai como a principal circunstância, com uma contribuição de $48,1 \%$ em 2013 e nas instituições privadas destacase a renda domiciliar per capita, com uma contribuição de 40,5\% em 2013.

\section{Agradecimentos}

Gostaríamos de agradecer a Maria Dolores Montoya Diaz, Rosana Rodrigues Heringer, Hustana Vargas e Danielle Carusi Machado por valiosos comentários e sugestões feitos na defesa de tese de M. Carvalho, tese que continha o 
estudo do qual se originou este artigo. Também somos gratos aos membros do Núcleo de Estudos em Educação, do Centro de Estudos em Desigualdade e Desenvolvimento da UFF (CEDE), que colaboraram em todas as etapas do desenvolvimento desta pesquisa. Também devemos agradecimentos a pareceristas anônimos deste periódico, que nos permitiram aprimorar a qualidade do trabalho. Os autores são os únicos responsáveis por esta versão final.

\section{Referências Bibliográficas}

Arneson, R. (1989), 'Equality of opportunity of welfare', Philos. Stud. 56, 7793.

Barr, N. (2012), Economics of the Welfare State, Oxford University Press.

Barros, R. P., Ferreira, F. H. G., Vega, J. R. M. \& Chanduvi, J. S. (2009), Measuring inequality of opportunities in latin américa and caribbean, Technical report, The World Bank. Washington D.C.

Bourguignom, F. (1979), 'Decomposable income inequality measures', Econometrica $47,901-920$.

Bowen, G. \& Bok, D. (2004), O curso do Rio: um estudo sobre a ação afirmativa no acesso à universidade, Garamond, Rio de Janeiro.

Carvalho, M. (2011), 'A educação superior no brasil: o retorno privado e as restrições ao ingresso', Revista Sinais Sociais 5(15), 82-109.

Carvalho, M., Gamboa, L. \& Waltenberg, F. (2012), Equality of education opportunity employing pisa data: taking both achievement and access into account, Working Paper Series 277, ECINEQ.

Cohen, G. (1989), 'On the currency of egalitarian justice', Ethics 99, 906-944.

Cowell, J. (1980), 'On the struture of additive inequality measures', Review of Economic Studies 47, 521-531.

Cruz, L. \& Moreira, M. (2005), 'On the validity of econometric techniques with weak instruments: Inference and returns to education using compulsory school attendance laws', Journal of Human Resources 40(2), 393-410.

Diaz, M. (2012), '(des)igualdades de oportunidades no ensino médio brasileiro: escolas públicas e privadas', Revista Economia 13(3), 553-568.

Dill, H. \& Gonçalves, F. (2012), 'Indice de oportunidade no brasil entre 1999 e 2009: estimação e decomposição através do valor de shapley', Pesquisa e Planejamento Econômico 42(2), 187-210.

Dworkin, R. (1981), 'What is equality? part 2: equality of resources', Philos Aff. 10, 283-345.

Ferreira, F. \& Gignoux, J. (2008), 'The measurement of inequality of opportunity: Theory and an application to latin america', Review of Income and Wealth 57(4), 622-657.

Ferreira, F. \& Gignoux, J. (2014), 'The measurement of educational inequality: Achievement and opportunity', World Bank Econ. 28(2), 210-246. 
Fleurbaey, M. (2008), Fairness, Responsability and Welfare, Oxford University Press.

Hoyos, A. \& Narayan, A. (2012), Inequality of opportunities among children: how much does gender matter?, in 'The World Development Report 2012: Gender Equality and Development'.

INEP (2011), Sinopse estatística da educação básica: Censo escolar, Technical report, INEP, Brasília: O Instituto.

IPEA (2008), Políticas sociais - acompanhamento e análise, Technical Report 15, IPEA.

Litchfield, J. (1999), Inequality: Methods and tools, Technical report.

URL: Disponivel em: <http://www.worldbank.org/poverty/inequal/index.htm>.

Mendonça, R. (2000), A oportunidade imperdível: expansão educacional e desenvolvimento humano no Brasil, PhD thesis, Instituto de Economia da Universidade Federal do Rio de Janeiro (UFRJ).

OCDE (2011), Education at a glance, Technical report, OCDE, Paris, Unesco.

Peragine, V. (2011), 'Review of "measuring inequality of opportunities in latin america and the caribbean"', Journal of Economic Inequality 9, 137-143.

Pignataro, G. (2012), 'Equality of opportunity: Policy and measurement paradigms', Journal of Economic Surveys .

Ramos, X. \& Van De Gaer, D. (2012), Empirical approaches to inequality of opportunity: Principles, measures, and evidence, Working Papers 259, ECINEQ Society for the Study of Economic Inequality.

Roemer, J. (1993), 'A pragmatic theory of responsibility for the egalitarian planner', Philos, Public Fff 22, 146-166.

Roemer, J. (1998), Equality of Opportunity, Harvard University Press.

Sastre, M. \& Trannoy, A. (2002), 'Shapley inequality decomposition by factor components: some methodological issues', Journal of Economics Supplement 9, 51-90.

Shorrocks, A. (1980), 'The class of additively decomposable inequality measures', Econometrica 48, 613-625.

Shorrocks, A. (1982), 'Inequality decomposition by factor components', Econometrica 50, 193-211.

Shorrocks, A. (1999), 'Decomposition procedures for distributional analysis: a unified framework based on shapely value', Department of Economics, University of Essex.

Vega, J. R. M., Barros, R. P., Saavedra, J. \& Giugale, M. (2010), Do our children have a chance?, in 'The 2010 Human Opportunity Report for Latin America and the Caribbean', Word Bank, Washington DC, p. 176 p. 

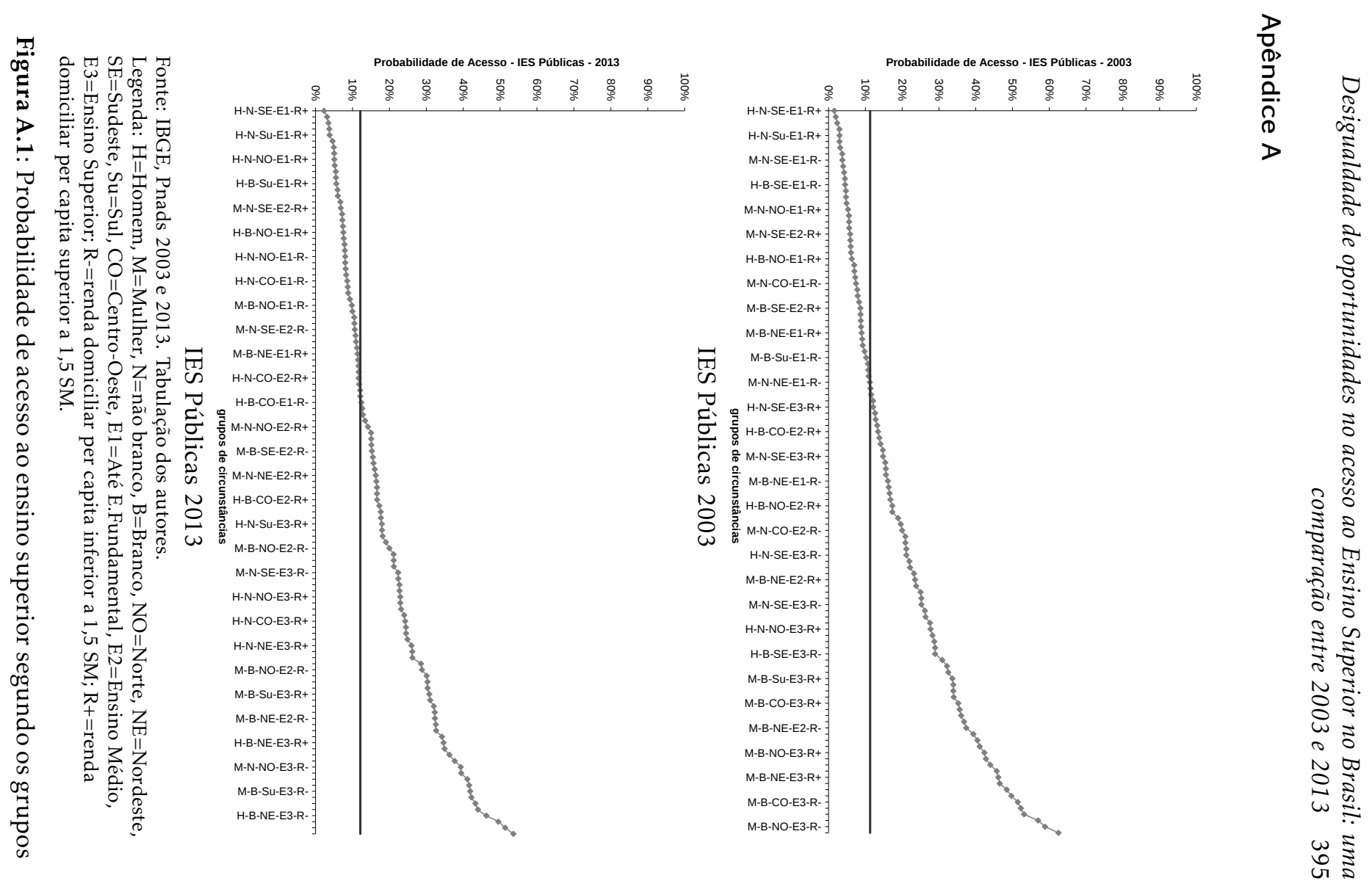


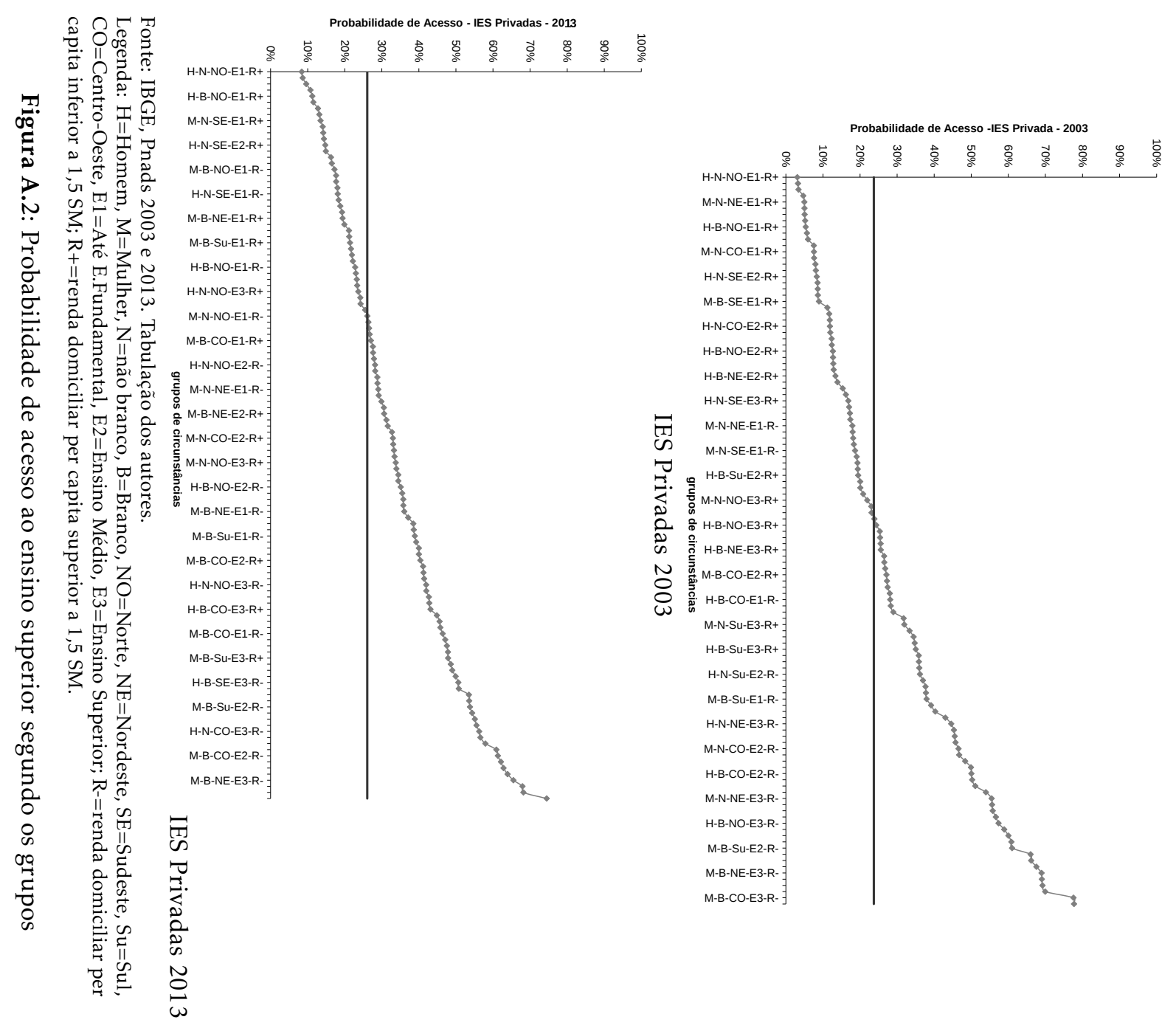

